\title{
Evaluaciones y medidas pretrasplante para prevención de infecciones
}

\section{Pre-transplant evaluations and management for infection prevention}

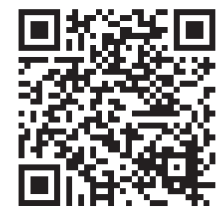

\author{
Jennifer Cuéllar-Rodríguez* \\ * Staff Clínico. Laboratorio de Microbiología Clínica e Inmunología. Instituto Nacional de Alergia y Enfermedades Infecciosas, Bethesda, MD, USA. \\ * Este manuscrito es a título personal y no representa la visión ni es avalado por el Instituto Nacional de Alergia y Enfermedades Infecciosas.
}

- El propósito de esta evaluación es determinar el riesgo de complicaciones infecciosas posteriores al trasplante renal y establecer medidas de prevención.

- El escrutinio general puede ser llevado a cabo por el equipo médico de trasplante, sin embargo, todos aquellos pacientes que son considerados de alto riesgo para desarrollar un evento infeccioso o aquéllos con una infección activa durante la valoración previa al trasplante renal deberán ser evaluados por el Servicio de Infectología., ${ }^{1,2}$

\section{EVALUACIÓN DEL RECEPTOR}

La evaluación clínica debe enfocarse en la exposición previa y actual a agentes infecciosos (serologías) y en el esquema de vacunación.

Los siguientes antecedentes en la historia de exposición o del riesgo de infección son una indicación para que se refiera al receptor a la consulta de infectología con serología pertinente en cada caso:

1. Viajar o vivir en zonas que sean de alto riesgo de infección por Coccidioides immitis (estados al norte de México y al sur de EUA). En caso positivo, se debe pedir serología para Coccidioides immitis y referir a la consulta de infectología con los resultados.

2. Viajar o vivir en zonas que sean de alto riesgo para enfermedad de Chagas (sureste mexicano, Centroamérica y Sudamérica), en cuyo caso se deberá pedir serología (prueba de ELISA, para escrutinio) para Trypanosoma cruzi (Chagas). En caso de resultar positivo, se deberá confirmar con otro método (por ejemplo, inmunofluorescencia indirecta). De confirmarse éste, debe referirse a la consulta de infectología con los resultados. También, en el caso de viajar o vivir en Asia (múltiples exposiciones), debe ser referido a infectología.

3. Historial de infecciones recurrentes (por ejemplo, infección de vías urinarias de repetición, infecciones asociadas con catéteres, materiales protésicos o historial de infecciones por microorganismos multidrogorresistente).

4. Conductas de alto riesgo para infecciones transmitidas por la sangre o por transmisión sexual.

5. Historial de infección por micobacterias (tuberculosis [TB]), hongos, toxoplasma o salmonela.

6. Historial familiar o contacto cercano con personas que hayan tenido tuberculosis.

Éstos son los estudios a realizarse en todos los candidatos a trasplante renal (Tabla 1).,1,2

Serologías indispensables

- Citomegalovirus (CMV) con inmunoglobulina G ( $\lg G)$.

- Virus Epstein-Barr (EBV): antígeno temprano o antígeno de cápside viral IgG, más antígeno nuclear de Epstein-Barr (EBNA) con IgG e IgM. 
Tabla 1: Pruebas de escrutinio de enfermedades infecciosas recomendadas previo al trasplante para donador y receptor.

\begin{tabular}{|c|c|c|c|c|}
\hline \multirow[b]{2}{*}{ Prueba } & \multirow[b]{2}{*}{ Receptor } & \multicolumn{2}{|c|}{ Donador } & \multirow[b]{2}{*}{ Obligatoriedac } \\
\hline & & Vivo & Fallecido & \\
\hline \multicolumn{5}{|l|}{ Infecciones virales } \\
\hline Citomegalovirus anticuerpos $\lg G$ & $\checkmark$ & $\checkmark$ & $\checkmark$ & Obligatorio \\
\hline $\mathrm{VIH}$ & $\checkmark$ & $\checkmark$ & $\checkmark$ & Obligatorio \\
\hline \multicolumn{5}{|l|}{ a. ELISA cuarta generación detección } \\
\hline de $\mathrm{Ag} / \mathrm{Ac}$ & 1a. elección & 1a. elección & 1a. elección & Deseable \\
\hline b. ELISA tercera generación & Alternativa & Alternativa & Alternativa & \\
\hline c. Amplificación de ácidos nucleicos & & En donadores de alto riesgo* & En donadores de alto riesgo $0^{\ddagger}$ & Deseable \\
\hline \multicolumn{5}{|l|}{ Virus de hepatitis B } \\
\hline VHBsAg, VHBcAc (total o lgG e lgM) & $\checkmark$ & $\checkmark$ & $\checkmark$ & Obligatorio \\
\hline VHBsAC & $\checkmark$ & & & Obligatorio \\
\hline \multicolumn{5}{|l|}{ Virus de hepatitis C } \\
\hline VHC AC & $\checkmark$ & $\checkmark$ & $\checkmark$ & Obligatorio \\
\hline a. Amplificación de ácidos nucleicos & & En donadores de alto riesgo* & En donadores de alto riesgo ${ }^{\ddagger}$ & Deseable \\
\hline b. Amplificación de ácidos nucleicos & En hemodiálisis & & Todos & Sugerido \\
\hline Virus hepatitis A lgG & $\checkmark$ & & & Sugerido \\
\hline \multicolumn{5}{|l|}{ Virus Epstein-Barr } \\
\hline a. Antígeno cápside viral lgG & $\checkmark$ & & & Obligatorio \\
\hline b. Antígeno cápside viral lgG & & $\checkmark$ & $\checkmark$ & Deseable \\
\hline \multicolumn{5}{|l|}{ c. Antígeno temprano Ac y antígeno } \\
\hline nuclear (EBNA) lgG & $\checkmark$ & $\checkmark$ & & Deseable $§$ \\
\hline Virus varicela zóster & $\checkmark$ & & & Deseable" \\
\hline Virus herpes simple 1 y 2 & $\checkmark$ & & & Sugerido \\
\hline \multicolumn{5}{|l|}{ Sarampión (sin antecedente de vacuna- } \\
\hline ción en la infancia) & $\checkmark$ & & & Sugerido \\
\hline \multicolumn{5}{|l|}{ Infecciones bacterianas } \\
\hline Sifilis: VDRL o FTA-ABS & $\checkmark$ & $\checkmark$ & $\checkmark$ & Obligatorio \\
\hline Tuberculosis & $\checkmark$ & $\checkmark$ & $\checkmark$ & Obligatorio \\
\hline a. PPD o IGRA (QuantiFERON TB) & $\checkmark$ & $\checkmark$ & & Obligatorio \\
\hline b. Radiografía de tórax & $\checkmark$ & $\checkmark$ & & Obligatorio \\
\hline c. Radiografía de tórax & & & $\checkmark$ & Deseable \\
\hline \multicolumn{5}{|l|}{ Otras } \\
\hline \multicolumn{5}{|l|}{ Coccidioidomycosis (sólo en regiones } \\
\hline endémicas-norte de México) & $\checkmark$ & $\checkmark$ & $\checkmark$ & Obligatorio \\
\hline Strongyloides Ac & $\checkmark$ & & & Sugerido \\
\hline Trypanosoma cruzi (Chagas) & $\checkmark$ & $\checkmark$ & $\checkmark$ & Sugerido \\
\hline Toxoplasmosis" & $\checkmark$ & $\checkmark$ & & Sugerido \\
\hline \multicolumn{5}{|l|}{ Cultivos } \\
\hline a. Urocultivo & & $\checkmark$ & & Obligatorio \\
\hline b. Urocultivo & $\checkmark$ & & $\checkmark$ & Sugerido \\
\hline c. Hemocultivo & & & $\checkmark$ & Sugerido \\
\hline d. Exudado nasal & $\checkmark$ & & & Deseable \\
\hline Coproparasitoscópico x3 & $\checkmark$ & & & Sugerido \\
\hline Evaluación dental & $\checkmark$ & & & Sugerido \\
\hline
\end{tabular}

* En donadores de alto riesgo para contraer infecciones trasmitidas por la sangre, se deberá realizar idealmente dentro de los 28 días previo a la donación.

$\ddagger$ En donadores de alto riesgo para contraer infecciones trasmitidas por la sangre.

$\S$ En pacientes pediátricos.

" En particular, en pacientes en los que no se cuenta con la cartilla de vacunación o en la ausencia de historia de haber padecido varicela durante la infancia.

" En particular, en candidatos alérgicos al trimetropim-sulfametoxazol (TMP-SMX).

$\lg \mathrm{G}=$ inmunoglobulina $\mathrm{G} ; \mathrm{Ac}=$ anticuerpos; $\mathrm{Ag}=$ antígeno; ELISA = Enzyme-Linked ImmunoSorbent Assay; VHBsAg = virus hepatitis B surface antigen; VHBcAc=Virus B hepatitis virus core antigen; $\mathrm{VHC}=$ virus de hepatitis C; VDRL = Venereal Disease Research Laboratory; FTA-ABS $=$ Fluorescent Treponemal Antibody Absorption; PPD $=$ Purified Protein Derivative. 
- Virus de varicela zóster con IgG (excepto si ya ha padecido varicela o herpes zóster).

- Virus de inmunodeficiencia humana (VIH).

- Prueba serológica de sífilis VDRL-escrutinio para sífilis.

- Virus de hepatitis A con IgG.

- Virus de hepatitis B (VHB): VHBsAg, VHBsAc, VHBcAc.

- Virus de hepatitis $\mathrm{C}(\mathrm{VHC}) .^{1-5}$

Serologías opcionales de acuerdo con el riesgo

- Strongyloides $s p$. (se considera endémico en todo México, por lo cual, si no se cuenta con serología, se recomienda administrar $200 \mu \mathrm{g} / \mathrm{kg}$ de ivermectina vía oral cada semana durante dos semanas).

- Tripanosoma cruzi.

- Coccidioides immitis.

\section{Otros estudios}

- PPD (purified protein derivative, por sus siglas en inglés) o ensayo de liberación de interferón gamma (IGRA, por sus siglas en inglés Interferon-Gamma Release Assay) (quantiFERON-TB o ELISPOT-TB) (véase el apartado de tuberculosis).

- Radiografía posteroanterior y lateral de tórax. En caso de que exista alguna anormalidad en la radiografía, se deberá realizar una tomografía computarizada de tórax.

- Examen general de orina y urocultivo. En caso de que el paciente tenga anuria (volumen urinario al día menor a $100 \mathrm{~mL}$ ) y se encuentre asintomático de la vía urinaria, se omitirá la realización de exámenes de orina.

- Cultivos de orina para micobacterias (véase el apartado de tuberculosis).

- Cultivos en pacientes con diálisis peritoneal, líquido de diálisis peritoneal (con cuenta celular).

- Exudado nasal en todos los pacientes.

- Coproparasitoscópico en tres ocasiones.

Todas las serologías que son negativas se deben repetir cada seis meses, además del día del trasplante. Las serologías tomadas el día del trasplante se revisarán posterior a éste para ajustar las medidas preventivas. Si cualquiera de las serologías es positiva, no es necesario repetirla cada seis meses; su riesgo se asume basándose en la primera determinación positiva.

En caso de que las serologías del virus de la varicela zóster y de los virus de la hepatitis $A$ y $B$ sean negativas, se debe vacunar lo más temprano posible durante la valoración antes del trasplante (véase el apartado de inmunizaciones).

En caso de que cualquiera de las siguientes serologías sea positiva, se debe referir al Servicio de Infectología y/o Hepatología: VIH, VDRL, VHBsAg, VHBcAc, VHC Ac.

En caso de que la serología de EBV (IgG contra antígeno temprano o antígeno de cápside viral) sea positiva y el EBNA IgG sea negativo con EBNA IgM positivo, debe repetirse la serología de cuatro a ocho meses posteriores a la determinación inicial y se deberá referir al Servicio de Infectología.

EI PPD o IGRA deberán repetirse anualmente en pacientes con estudios negativos previos. Si alguno de estos estudios es positivo, no es necesario repetirlos. Se asume el riesgo con base en la primera determinación positiva. ${ }^{1}$

\section{Tuberculosis}

La tuberculosis (TB) en receptores de trasplante renal representa un reto terapéutico, además de que se asocia con una elevada tasa de mortalidad. Los receptores de trasplante de un órgano sólido tienen un riesgo sustancialmente mayor de adquirir TB que la población general. La incidencia de esta enfermedad en receptores de trasplante varía de acuerdo con la incidencia de esta enfermedad en la población general; en países desarrollados es de 1.2 a $6.4 \%$, mientras que la incidencia en regiones altamente endémicas es de hasta el $12 \%$. Ésta ha demostrado ser al menos cuatro veces la de la población general, y en algunos estudios casi 30 veces a la de la población general. ${ }^{6,7}$

\section{Escrutinio de tuberculosis de manera previa al trasplante}

La historia clínica debe explorar, de forma dirigida, la exposición de las personas con tuberculosis, los síntomas de tuberculosis, la historia de tuberculosis y los factores de riesgo. Entre los factores más comunes, más allá de vivir o haber viajado a regiones altamente endémicas, se encuentran: antecedente de haber estado en una prisión, en particular, dos años previos a la evaluación; haber estado en condición de refugiado o migrante indocumentado, tener familiares cercanos que sean tosedores crónicos y que tenga alguno de estos factores de riesgo.

Todos los candidatos a trasplante deberán contar con un PPD y/o IGRA. EI PPD se considerará positivo 
cuando la lectura sea $\geq 5 \mathrm{~mm}$. En caso de ser negativo, se solicitará un nuevo PPD 2-4 semanas después de la primera aplicación (booster). ${ }^{6,8}$

EI PPD o IGRA deberán repetirse anualmente en pacientes con estudios negativos previos. Si alguno de estos estudios es positivo, no es necesario repetirlos.

\section{Diagnósticos y manejo}

Sin infección por tuberculosis. Esto es PPD y/o IGRA negativo, sin síntomas sugestivos de tuberculosis y sin antecedentes de alto riesgo para tuberculosis, como: haber estado en contacto con personas que tengan o tuvieron tuberculosis, por ejemplo, migrantes o prisioneros. Su manejo no requiere tratamiento. Todo paciente que vive en México puede exponerse después del trasplante, por lo que una persona no tenga TB o se exponga a TB de manera previa al trasplante, no excluye que pueda desarrollarlo después del trasplante.

Tuberculosis latente (TBL). Esto es, PPD o IGRA positivo, sin síntomas sugestivos de tuberculosis, radiografía de tórax/tomografía computarizada de tórax sin lesiones sugestivas de enfermedad activa $y$, en caso de haberse obtenido, cultivos negativos. ${ }^{6,9}$

El manejo es el siguiente: $300 \mathrm{mg}$ de isoniacida vía oral, una vez al día durante nueve meses, combinado con piridoxina para prevenir neurotoxicidad. El trasplante puede realizarse en cualquier momento, aunque es deseable iniciar el tratamiento de TB latente uno a dos meses previos al trasplante.

En pacientes en hemodiálisis, la dosis diaria deberá administrarse de manera posterior a la hemodiálisis.

Si el tratamiento no se completó antes del trasplante, se deberá completar después de éste.

En los siguientes casos, se deberá considerar el tratamiento de TBL, a pesar de que los estudios PPD y/o IGRA sean negativos:6,8

- Lesiones fibróticas o calcificadas, sugestivas de TB antigua que no han recibido tratamiento de TB o TBL previamente.

- Individuos con historia de exposición certera.

- PPD o IGRA previo positivo.

- Pacientes provenientes de zonas con alta endemicidad (incidencia de TB $>20$ casos $/ 100,000$ personas).

Tuberculosis activa. Ocurre cuando el cultivo es positivo para Mycobacterium tuberculosis o BAAR (prueba de bacilos acidorresistentes) en muestras de expectoración o en histopatología sugestiva, o bien los síntomas son sugestivos en regiones endémicas. Se debe determinar el manejo en conjunto con el Servicio de Infectología.

El manejo es el siguiente: tratamiento con cuatro drogas (infectología) por el tiempo que corresponda al tipo de TB. Sólo se debe realizar el trasplante cuando se cumplan TODOS los siguientes requisitos: ${ }^{6,8}$

- Al menos dos meses de tratamiento.

- Evidencia de mejoría clínica.

- Los cultivos para micobacterias sean negativos.

- En caso de que el trasplante ocurra antes de terminar el esquema de tratamiento antituberculosis, se debe continuar con éste en el periodo posterior al trasplante.

\section{Citomegalovirus}

A todos los candidatos y potenciales donantes de trasplante renal se les debe solicitar serología para citomegalovirus (CMV) IgG. La importancia de esta serología es determinar el riesgo para el desarrollo de enfermedad por CMV en la etapa postrasplante..$^{10,11}$

\section{El riesgo puede clasificarse en:}

- Riesgo bajo. Esto se da cuando la serología (lgG) es negativa en el donador y en el receptor.

- Riesgo alto. Sucede cuando la serología es positiva en el donador y negativa en el receptor, siendo el mecanismo de infección una primoinfección por CMV. También se consideran de riesgo aumentado aquellos pacientes que reciban terapias de depleción linfocítica, tales como timoglobulina, entre otros.

- Riesgo intermedio. Se refiere a cuando la serología del receptor es positiva y la serología del donador es positiva o negativa. El mecanismo de infección es reactivación de CMV o infección de novo (presente en el donador).

Cuando la serología del donador o del receptor sea negativa y tenga más de un mes previo al trasplante, se deberán repetir las pruebas al momento de su internamiento para el trasplante (el resultado puede revisarse después del trasplante).

La mejor estrategia es aquélla que puede llevarse a cabo en forma continua. Todos los centros de trasplante deben establecer medidas de prevención después del trasplante, ya sea mediante profilaxis universal o terapia anticipada: ${ }^{12,13}$ 
A. Profilaxis universal. Consiste en administrar un fármaco útil en la prevención de CMV, ya sea valganciclovir (VGC) oral o ganciclovir vía intravenosa (GCV) a dosis profilácticas durante los primeros tres a seis meses posteriores al trasplante. Al término de la profilaxis, deberá efectuarse la monitorización con carga viral de CMV (alternativamente puede usarse antigenemia pp65) semanalmente durante las dos primeras semanas y quincenalmente durante las seis semanas subsecuentes. La positivización del ensayo es indicación para que se administren dosis terapéuticas de VGC vía oral o GCV vía intravenosa.

B. Terapia anticipada. En pacientes de alto riesgo o riesgo intermedio, se podrá monitorear semanalmente la replicación de CMV con carga viral (DNA o RNA) cuantitativa durante las primeras 12 semanas posteriores al trasplante. De manera alternativa, podrá realizarse antigenemia pp65 semanal. En casos en los que se positivice la carga viral (establecer un umbral institucional) o la antigenemia pp65, se deberán iniciar dosis terapéuticas de VGC VO o GCV IV. Los pacientes de riesgo bajo no requieren monitorización rutinaria ni profilaxis universal.

\section{Virus de inmunodeficiencia humana}

La infección por VIH no se considera una contraindicación para ser receptor de trasplante renal, sin embargo, se requiere la evaluación y el seguimiento del Servicio de Infectología para que se asegure de que el paciente esté adecuadamente controlado de la infección y de que se optimice el tratamiento, con el objetivo de minimizar las interacciones farmacológicas entre los antirretrovirales y los inmunosupresores.

A todos los candidatos y donantes potenciales, se les debe realizar una prueba de detección serológica de VIH (prueba ELISA).

- En candidatos y donantes vivos esta prueba en caso de ser negativa, se debe repetir anualmente e idealmente dentro de los 28 días previos al trasplante.

- Es deseable que la prueba de escrutinio sea una prueba ELISA de cuarta generación con detección de antígeno p24/anticuerpo contra VIH.

- Se puede hacer, de manera alternada, una prueba ELISA de tercera generación para la detección de anticuerpos contra VIH. Hay que tener en cuenta que esta prueba es inferior en sensibi- lidad y especificidad para la detección de infección por VIH.

\section{Virus de hepatitis B}

Todos los candidatos y donantes potenciales deben tener una prueba para la detección de infección por VHB con determinación de VHBsAg y VHBcAc. Los candidatos a trasplante renal deberán tener una prueba de detección de VHBsAc. Además, en candidatos o donantes vivos en quienes se obtenga una determinación positiva de VHBsAg o VHBcAc, se debe realizar una determinación cuantitativa de carga viral de VHB-ADN. A los candidatos y donantes vivos, cuyas pruebas serológicas sean negativas, se les debe repetir estas pruebas anualmente, e idealmente dentro de los 28 días previos al trasplante. En caso de que el candidato a trasplante tenga VHBsAc negativo, es necesario vacunarlo contra hepatitis B (véase el apartado de inmunizaciones).

\section{Virus de hepatitis C}

Todos los candidatos y donantes potenciales deben tener una prueba de detección de infección por VHC. En donantes fallecidos y en donadores vivos de alto riesgo, es deseable realizar pruebas de detección de ácido nucleicos de VHC. Estas pruebas permiten detectar oportunamente infecciones, ya que mediante éstas el periodo de ventana es significativamente menor que con las pruebas serológicas, lo que se traduce en un menor riesgo de transmisión de enfermedad. Asimismo, permite utilizar órganos que hubiesen sido descartados por provenir de donadores de alto riesgo.

En candidatos o donantes vivos en quienes la serología de VHC es positiva, se debe realizar una determinación cuantitativa de carga viral de VHC-ARN. En candidatos y donantes vivos la prueba serológica se deberá repetir anualmente en caso de resultar negativa, e idealmente dentro de los 28 días previos al trasplante. La infección por VHC en el receptor no es una contraindicación para el trasplante, pero, en caso de requerirse, será necesario evaluar la necesidad de tratamiento y el momento óptimo para hacerlo.

\section{Evaluación del donador}

La evaluación clínica debe enfocarse en la exposición actual y previa a agentes infecciosos (serologías y otros ensayos). Los siguientes antecedentes que se presenten en la historia clínica como indicadores de 
exposición o riesgo de infección son mandatorios para referir a la consulta de Infectología con serología pertinente en cada caso:

1. Viajar o vivir en zonas de alto riesgo para contraer Coccidioides immitis (estados al norte de México y al sur de Estados Unidos). En caso de resultar positivo, se debe pedir serología para Coccidioides immitis y, con los resultados, referir al Servicio de Infectología.

2. Viajar o vivir en zonas de alto riesgo para enfermedad de Chagas (sureste mexicano, Centroamérica y Sudamérica), en cuyo caso se debe pedir serología (prueba ELISA para escrutinio) para $T$. cruzi (Chagas) y, en caso de resultar positivo, se debe confirmar con otro método (por ejemplo, con inmunofluorescencia indirecta). De confirmarse, se debe referir al Servicio de Infectología con los resultados. También aplica en el mismo caso de viajar o vivir en zonas en Asia (múltiples exposiciones), en cuyo caso, se debe referir de igual manera al Servicio de Infectología.

3. Historial de infecciones recurrentes, en particular, del tracto urinario.

4. Conductas de alto riesgo de infecciones transmitidas por la sangre o transmisión sexual.

5. Historial de infección por micobacterias (tuberculosis [TB]), hongos, toxoplasma o salmonela.

6. Historial de algún familiar o contacto cercano con personas que hayan tenido tuberculosis.

Serologías indispensables

- Citomegalovirus (CMV) con inmunoglobulina G.

- Virus Epstein-Barr: antígeno temprano o antígeno de cápside viral con inmunoglobulina $\mathrm{G}$ más antígeno nuclear de Epstein-Barr (EBNA) con inmunoglobulina G.

- Virus de inmunodeficiencia humana.

- Prueba serológica de sífilis VDRL (escrutinio para sífilis).

- Virus de hepatitis B: VHBsAg, VHBsAc.

- Virus de hepatitis C.

Estudios opcionales de acuerdo con el riesgo

- Serología para Trypanosoma cruzi.

- Serología para Coccidioides immitis.

- En donadores de alto riesgo de infecciones trasmitidas por la sangre (véase en el apartado de dona- dores de alto riesgo), se debe realizar una prueba de detección de ácidos nucleicos para $\mathrm{VIH}, \mathrm{VHC}$ y VHB.

\section{Otros estudios}

- PPD o ensayo de liberación de interferón gamma (IGRA) (QuantiFERON-TB o ELISPOT-TB) (véase el apartado de tuberculosis).

- Radiografía posteroanterior de tórax. En caso de que exista alguna anormalidad en la radiografía, se deberá realizar una tomografía computarizada de tórax.

- Examen general de orina y urocultivo.

- Cultivos de orina para micobacterias (solo en donadores de riesgo) (véase el apartado de tuberculosis).

\section{Otras recomendaciones}

- En caso de que la serología IgG para el antígeno de la cápside del virus Epstein-Barr sea positiva y la prueba EBV EBNA con IgG sea negativa, se deberá repetir en dos semanas y, en caso de donadores vivos, referir al Servicio de Infectología. En donadores fallecidos, habrá que vigilar al receptor de acuerdo con el riesgo serológico con PCR.

- En caso de resultar VDRL positivo, se deberá evaluar la presencia de sífilis con una prueba treponémica y, en caso de confirmarse, ésta deberá tratarse antes de la donación. En donadores vivos, es necesario referir al Servicio de Infectología; en donadores fallecidos, tratar al receptor.

\section{Tuberculosis}

- Todo potencial donador debe tener una radiografía posteroanterior de tórax y contar con un PPD y/o IGRA. EI PPD se considera positivo cuando la lectura es $\geq 10 \mathrm{~mm}$, y negativo si es $<10 \mathrm{~mm}$. En potenciales donantes en que el escrutinio para TBL es positivo (ya sea por contacto de riesgo, el PPD > $10 \mathrm{~mm}$ o IGRA positivo o la radiografía es sugestiva de enfermedad previa), es necesario descartar TB activa.

\section{Estudios de extensión}

- Se realizará búsqueda de prueba de bacilos acidorresistentes y cultivo para micobacterias en tres muestras de expectoración o jugo gástrico si hay síntomas como: tos, dolor torácico, fiebre, pérdida de peso; y/o alteraciones en la radiografía. 
- Se realizará cultivo para micobacterias en tres muestras de orina si existen alteraciones en el sedimento urinario sin otra explicación, o alteraciones en el tracto genitourinario que puedan sugerir lesiones cicatriciales por TB.

- Los potenciales donantes con PPD o IGRA positivo, sin síntomas de TB y cultivos negativos tienen diagnóstico de tuberculosis latente. Se desconoce el beneficio real para el receptor de tratar la TBL en el donador, por lo cual si se sabe que el donador se beneficia del tratamiento (ej. PPD conversión reciente $<2$ años, o exposición certera previa) es necesario tratar al donador; si no es el caso, se debe tratar al receptor de acuerdo con el riesgo de toxicidad. Es importante que no se retrase el trasplante.
- Se puede considerar tratar con isoniacida 300 $\mathrm{mg} / \mathrm{día}$ por nueve meses.

- Si el riesgo de TB es bajo, no se requiere posponer el trasplante. En los pacientes en los que se consideró necesario tratar la TBL en el donante y el donador no completó tratamiento de TBL previo a la donación, se debe tratar al receptor para TBL.

- En donantes fallecidos, el escrutinio para TBL consiste en interrogatorio dirigido de TB previa, contactos con personas con TB u otros factores de riesgo (cárcel en los últimos dos años). Se sugiere complementar con radiografía de tórax, y tratar al receptor en caso de ser un donante de riesgo de TB.

- En donantes fallecidos, la historia de haber padecido tuberculosis activa, la cual fue tra-

Tabla 2: Esquema de vacunación recomendado.

\begin{tabular}{|c|c|c|}
\hline Vacuna & Dosis & Indicación \\
\hline \multicolumn{3}{|l|}{ Vacunas no vivas-recomendadas } \\
\hline \multirow[t]{2}{*}{ Influenza (inyectada) trivalente, cuadrivalente (dosis alta) } & Anual & Todos \\
\hline & Idealmente previo al trasplante & \\
\hline Vacuna neumocócida polisacárida (PPSV-23) & Cada 5 años & Todos \\
\hline \multirow[t]{2}{*}{ Vacuna neumocócida conjugada (PCV-13) } & Una dosis de por vida (adultos) & Todos \\
\hline & & $\begin{array}{l}\text { Idealmente } 8 \text { semanas antes de la primera dosis } \\
\text { de PPSV-23. Si ya se aplicó PPSV-23, esperar un } \\
\text { año antes de aplicar la dosis }\end{array}$ \\
\hline Hepatitis B o serie combinada hepatitis A/B & $\begin{array}{l}B(0,1 \text { y } 6 \text { meses, } 40 \mu \mathrm{g} \text { por dosis }) \\
A / B(0,1 \text { y } 6 \text { meses })\end{array}$ & $\begin{array}{l}\text { En candidatos seronegativos para virus hepatitis B } \\
\text { (VHBsAc). Utilizar dosis alta de la vacuna de Virus } \\
\text { de hepatitis B }\end{array}$ \\
\hline \multicolumn{3}{|l|}{ Vacunas no vivas-deseables } \\
\hline TDAP (tétanos, difteria, pertussis acelular) & Una dosis & Al menos una vez en la edad adulta \\
\hline Virus del papiloma Humano (4 09 valente) & 3 dosis (0, $1-2$ y 6 meses) & Candidatos mujeres u hombres ( 9 a 45 años) \\
\hline \multicolumn{3}{|l|}{ Vacunas no vivas-sugeridas } \\
\hline Haemophilus influenzae tipo B (HiB) & 1 dosis & Candidatos que puedan requerir esplenectomía \\
\hline Meningococo cuadrivalente & 2 dosis (> 8 semanas entre ambas) & Candidatos que puedan requerir esplenectomía o \\
\hline Meningococo serogrupo B & $\begin{array}{l}\text { Vacuna multicomponente de amplio espectro contra el } \\
\text { meningococo- proteína de unión factor } \mathrm{H} \text { lipoproteína } \\
\text { (MenB-FHbp): } 3 \text { dosis ( } 6 \text { meses separación) }\end{array}$ & eculizumab; u otro riesgo de exposición \\
\hline \multicolumn{3}{|c|}{ Vacunas vivas - sugeridas* } \\
\hline \multicolumn{3}{|c|}{ (En todos los casos no deben de estar bajo inmunosupresión o dentro de las 4 semanas previo al trasplante) } \\
\hline & 2 dosis (4 a 8 semanas de separación) & seronegativos \\
\hline Zóster (Zostavax) $)^{\ddagger}$ & 2 dosis (2 a 6 meses de separación) & En candidatos $>50$ años \\
\hline Sarampión, paperas, rubéola (MMR) & 1 a 2 dosis (> 28 días de separación) & $\begin{array}{l}\text { Si nació después de } 1965 \text { y no hay documentación } \\
\text { de haber recibido dos dosis de la vacuna MMR en } \\
\text { el pasado o de acuerdo a serología }\end{array}$ \\
\hline
\end{tabular}

* Contraindicadas en pacientes inmunocomprometidos. No deben estar en las cuatro semanas previas al trasplante.

‡ La vacuna contra zóster recombinante RZV (Shingrix) no contiene virus vivos y podría aplicarse en cualquier momento antes o después del trasplante. La vacuna contra zóster de virus vivos (Zostavax) contiene virus vivos, y una dosis mucho más alta que la vacuna de la varicela, ésta sólo puede aplicarse en adultos mayores no inmunocomprometidos al menos cuatro semanas previo al trasplante. 
tada adecuadamente. Ésta no es razón para excluirlo como donante, sin embargo, en estos casos, debe hacer un interrogatorio exhaustivo e indagar las particularidades del tratamiento para determinar que el potencial donante efectivamente recibió un tratamiento adecuado.

- En receptores de donantes con TB tratada en los últimos dos años, se recomienda tratar al receptor para TBL.

- En receptores de donantes en quienes se desconoce el tiempo y tipo de tratamiento, se recomienda tratar al receptor para TBL y considerar hacer tinciones y cultivos para micobacterias de ganglios y/o tejidos.

- Todos los casos en que el potencial donante sea un donador de alto riesgo, es necesario obtener el consentimiento informado en el receptor.

Donadores de alto riesgo para trasmitir el virus por medio de la sangre

1. Hombres que tienen relaciones sexuales con su mismo sexo (1 a).

2. Personas que usan drogas inyectables ( $1 \mathrm{a}$ ).

3. Individuos que tienen relaciones sexuales a cambio de dinero o drogas (1 a).

4. Personas que tienen relaciones sexuales con personas que se sospecha o sabe que tienen $\mathrm{VIH} /$ $\mathrm{VHC/VHB} \mathrm{(1} \mathrm{a).}$

5. Individuos que tienen relaciones sexuales con cualquiera que tenga los factores de riesgo 1 a 4 .

6. Haber estado encarcelado por más de 72 horas (1 a).

7. Historial de haber padecido sífilis, gonorrea, clamidia o úlceras genitales (1 a).

8. Hijo de una madre que es de riesgo $(<18$ meses edad).

9. Lactancia de madre infectada por $\mathrm{VIH}(1 \mathrm{a})$.

10. Antecedente de haber requerido hemodiálisis en algún momento (1 a).

\section{Inmunizaciones}

- Se recomienda que todo candidato a trasplante renal tenga sus inmunizaciones actualizadas.

- Se sugiere revisar la cartilla de vacunación, y actualizar todas las que estén incompletas.

- La respuesta a las vacunas es más efectiva en el periodo pretrasplante, por lo que es deseable actualizarlas desde que un paciente empieza a considerarse candidato a trasplante. Sin embargo, si no ha completado un esquema o no ha recibido una vacuna, no significa que sea una contraindicación para el trasplante. ${ }^{14-17}$

- Si los esquemas de vacunación no se completan en el periodo pretrasplante, éstos deberán completarse posterior al trasplante.

- Las únicas vacunas contraindicadas posteriores al trasplante son aquellas provenientes de microorganismos vivos atenuados, por lo cual, si un paciente las requiere, éstas deberán administrarse al menos cuatro semanas previas al trasplante, siempre y cuando el paciente no se encuentre inmunosuprimido (Tabla 2). ${ }^{14-17}$

\section{REFERENCIAS}

1. Malinis M, Boucher HW, AST Infectious Diseases Community of Practice. Screening of donor and candidate prior to solid organ transplantation-Guidelines from the American Society of Transplantation Infectious Diseases Community of Practice. Clin Transplant. 2019; 33 (9): e13548. doi: 10.1111/ctr.13548.

2. Kasiske BL, Cangro CB, Hariharan S, Hricik DE, Kerman RH, Roth $\mathrm{D}$ et al. The evaluation of renal transplantation candidates: clinical practice guidelines. Am J Transplant. 2001; 1 (Suppl 2): 3-95.

3. Avery RK. Recipient screening prior to solid-organ transplantation. Clin Infect Dis. 2002; 35 (12): 1513-1519.

4. Fischer SA, Avery RK; AST Infectious Disease Community of Practice. Screening of donor and recipient prior to solid organ transplantation. Am J Transplant. 2009; 9 Suppl 4: S7-18.

5. Delmonico FL. Cadaver donor screening for infectious agents in solid organ transplantation. Clin Infect Dis. 2000; 31 (3): 781-786.

6. Subramanian AK, Theodoropoulos NM; Infectious Diseases Community of Practice of the American Society of Transplantation. Mycobacterium tuberculosis infections in solid organ transplantation: Guidelines from the infectious diseases community of practice of the American Society of Transplantation. Clin Transplant. 2019; 33 (9): e13513. doi: 10.1111/ctr.13513.

7. Jung JY, Joo DJ, Lee CH, Park MS, Kim YS, Kim MS et al. Pretransplant risk factors for tuberculosis after kidney transplant in an intermediate burden area. Int J Tuberc Lung Dis. 2012; 16 (2): 248-254.

8. Torre-Cisneros J, Doblas A, Aguado JM, San Juan R, Blanes $\mathrm{M}$, Montejo $\mathrm{M}$ et al. Tuberculosis after solid-organ transplant: incidence, risk factors, and clinical characteristics in the RESITRA (Spanish Network of Infection in Transplantation) cohort. Clin Infect Dis. 2009; 48 (12): 1657-1665.

9. Morris MI, Daly JS, Blumberg E, Kumar D, Sester M, Schluger $\mathrm{N}$ et al. Diagnosis and management of tuberculosis in transplant donors: a donor-derived infections consensus conference report. Am J Transplant. 2012; 12 (9): 2288-2300.

10. Razonable RR, Humar A. Cytomegalovirus in solid organ transplant recipients-Guidelines of the American Society of Transplantation Infectious Diseases Community of Practice. Clin Transplant. 2019; 33 (9): e13512. doi: 10.1111/ctr.13512.

11. Humar A, Mazzulli T, Moussa G, Razonable RR, Paya CV, Pescovitz MD et al. Clinical utility of cytomegalovirus (CMV) serology testing in high-risk CMV D+/R- transplant recipients. Am J Transplant. 2005; 5 (5): 1065-1070.

12. Humar A, Lebranchu $Y$, Vincenti $F$, Blumberg EA, Punch JD, Limaye AP et al. The efficacy and safety of 200 days 
valganciclovir cytomegalovirus prophylaxis in high-risk kidney transplant recipients. Am J Transplant. 2010; 10 (5): 1228-1237.

13. Razonable RR, Hayden RT. Clinical utility of viral load in management of cytomegalovirus infection after solid organ transplantation. Clin Microbiol Rev. 2013; 26 (4): 703-727.

14. Danziger-Isakov L, Kumar D, AST ID Community of Practice. Vaccination of solid organ transplant candidates and recipients: Guidelines from the American society of transplantation infectious diseases community of practice. Clin Transplant. 2019; 33 (9): e13563. doi: 10.1111/ctr.13563.

15. Pergam SA, Limaye AP, AST Infectious Diseases Community of Practice. Varicella zoster virus in solid organ transplantation: Guidelines from the American Society of Transplantation Infectious Diseases Community of Practice. Clin Transplant. 2019; 33 (9): e13622. doi: 10.1111/ctr.13622.
16. Blanchard-Rohner G, Enriquez N, Lemaître B, Cadau G, Combescure C, Giostra E et al. Usefulness of a systematic approach at listing for vaccine prevention in solid organ transplant candidates. Am J Transplant. 2019; 19 (2): 512-521. doi: 10.1111/ajt.15097.

17. Chong PP, Avery RK. A Comprehensive review of immunization practices in solid organ transplant and hematopoietic stem cell transplant recipients. Clin Ther. 2017; 39 (8): 1581-1598. doi: 10.1016/j.clinthera.2017.07.005.

Correspondencia:

Dra. Jennifer Cuellar-Rodríguez

E-mail: jennifer.cuellarrodriguez@ nih.gov 